pointed out, little is known of nitrogen fixation by marine organisms. Dr. Allen gave an account of how she is growing pure cultures of freshwater nitrogen-fixing, blue-green algae under saline conditions, and reported the effect of this on their capacity for nitrogen fixation.

Dr. M. R. Droop (Scotland) discussed evidence for and against the view that vitamin $B_{12}$ may become a limiting nutrient for phytoplankton populations in the sea. The mass culture of marine phytoplankton was reviewed by Dr. G. E. Fogg (England), who concluded that it was unlikely to become a practical proposition, at least until harvesting difficulties could be overcome.

Dr. J. W. Kanwisher (United States) reported on a new method of continuous oxygen recording which has been used for measuring the photosynthetic and respiratory capacity of several intertidal algae.

Details of a mothod of physode estimation were given by Dr. E. Baardseth (Norway), who found that the percentage physode volume varied from species to species and in Ascophyllum, with variation in salinity and habitat.
Prof. H. A. von Stosch (Germany) discussed similarities between the leucosin of diatoms and chrysomonads and the laminarin of Phaeophyta. $\mathrm{He}$ gave evidence to support the conclusion that these substances are closely related.

The main symposium was followed by a single-day symposium on "Intertidal Ecology".

The time available for discussion following each paper was very limited, but there were ample opportunities for private discussion at the various shorecollecting excursions and social functions run in connexion with the symposium. It was agreed that the complete text of the papers presented should not be published. The fourth International Seaweed Symposium is to be held in France in September, 1961, and an Advisory Committee consisting of Prof. T. Braarud (Norway), Dr. T. Dillon (Ireland), Prof. T. Levring (Sweden), Dr. A. D. de Virville (France), Dr. F. N. Woodward (Great Britain) and Dr. E. G. Young (Canada) was appointed to assist the French National Committee in drawing up a programme.

\section{W. D. RichaRdon}

E. T. Dewar

\title{
INTERNATIONAL CONFERENCE ON SCIENTIFIC MEASUREMENTS
}

$\mathrm{A}^{\mathrm{N}}$ $\mathrm{N}$ international conference on the theoretical and practical problems involved in making scientific measurements was held in Budapest during November 24-29. Part of the conference was held in the building which was formerly the Stock Exchange but is now the home of the engineering societies and is re-named Technika Háza. The other meetings were held in the Rózsa Ferenc House of Culture. Some 250 foreign and 460 Hungarian scientists took part in the conference, and representatives came from twenty-three countries. Academies of science in a number of countries, including France, Italy and Sweden, either sent representatives or gave their official support to the conference.

Some 160 papers were read, 127 of them by nonHungarian scientists. The papers were divided into a number of sections with the following titles : mechanical and optical, electrical and electronic, thermal, physico-chemical and nuclear-physical. There were also papers on the economics of instrument production, and an informal discussion was held between the university teachers present to discuss student courses for measuring techniques and instrument-making. Though there were many papers of considerable individual merit, one difficulty emerged during the conference, namely, that in some sections the papers were too diverse in character to form a coherent whole. Summaries of most of the papers were published in two booklets, mostly in the German language, though some were given in English, French or Russian.

The Hungarian Chamber of Commerce arranged an exhibition of Hungarian scientific instruments in the Technika Háza. The well-known skill of Hungarians in arranging exhibitions was clearly shown here. Though there were gaps in the range of instruments exhibited, the level of instrument technology in the fields covered appeared to be high.

This conference was called by three organizations acting jointly, one Hungarian, one in the Soviet Union and one in Poland. The Presiding Council hopes to prepare a further conference, probably in 1961, and to enlarge the national representation on the committee which will organize it.

Visits to scientific institutes in the Eötvös Lorand and the Technical Universities and in the Academy of Sciences were arranged. There was also a social programme which included visits to the opera, theatre and cinema. Those attending the conference were very conscious of their debt to the members of the staff of the Hungarian Federation of Scientific Societies for the care which they took in ensuring the comfort and the convenience of visitors. W. A. WOOSTER

\section{THE FUTURE OF ANTARCTICA}

\begin{abstract}
"THAT a new era in Antarctica indeed is opening needs clearer recognition. Suddenly Antarctica now has applied to it the resources, the techniques and the wealth of experience from no less difficult operations in the Arctic. The United States preeminently, and Russia not far behind, both possess and feel it expedient now for the first time to use great resources in Antarctica on a scale without precedent. Their northern experience is immense.
\end{abstract}

Yet great resources of men and materials are not deployed by even the very powerful without strong reasons."

"Political stability in Antarctica in the next few years is certainly improbable. The post-war realignment of the nations in terms of modern power and resources is now in process of extending to Antarctica. ... Now is the time for realism and re-appraisal by the sovereign states of Antarctica." 
These quotations from the published version* of the lectures delivered by Dr. G. C. L. Bertram while he was William Evans visiting professor in the University of Otago in 1957 indicate well the nature of his theme. Dr. Bertram, who was director of the Scott Polar Research Institute at Cambridge during 1949-57, speaks with authority about Antarctica, and in this thought-provoking essay he speaks with evident concern. He recognizes and discusses five motives that may underlie rational activity in Antarctica-the adventurous, economic, scientific, political and strategic motives, and from his discussion there emerges a picture of the present situation in which the last two named are dominant, a situation in strong contrast to that which obtained in the first twenty years of this century when British expeditions dominated the Antarctic scene and interest was primarily adventurous and secondarily scientific. Dr. Bertram examines the probable motivation of the twelve nations that may be said to-day to have Antarctic 'aspirations' or 'interests'. Five of these-Australia, France, Great Britain, New Zealand and Norway-lay formal claim to sectors of Antarctic territory which cover about four-fifths of the continent. The sovereignty of these five mutually recognizing Powers is, however, not admitted by the United States and the U.S.S.R., the two Powers deploying greatest resources in the Antarctic, and is openly flouted by others. Time, Dr. Bertram insists, is not upon the side of the five, and their position is not helped by their comparative grave weakness in shipping suitable for the maintenance of their Antarctic interests. "Not one of the five," he remarks, "has the full manœuvrability and appear-

* Antarctica Today and Tomorrow. By Prof. G. C. L. Bertram. Pp. ii +28 . (Cambridge: At the University Press; Melbourne: Melbourne University Press, 1958.) 5s. net. ance of power only to be given by the possession of a genuine ice-breaker. On the other hand, Russia, the United States and Argentine have admirable such vessels, and even Chile has building a ship superior to anything possessed or yet being built by the five. Our grandfathers must turn in their graves at this astonishing change in maritime power and forethought and at the depths to which the British Commonwealth has sunk." There is an over-riding. need, Dr. Bertram thinks, for consultation by the five, and first and especially by the three Commonwealth countries, and a re-appraisal leading to a constructive plan. "When the passage of time may" seem to give advantage to the rival or adversary, then it is often rationally expedient to seize the initiative."

Dr. Bertram considers some of the theoretical possibilities for the future political evolution of Antarctica, namely, recognition of existing claims (and here he notes how much this would be aided if the United States even now were to lay claim, as it has excellent reason for doing, to the remaining unclaimed Pacific sector); sale of Antarctic territory; condominium, possibly under the United Nations Organization; partition into territories each administered by members of the United Nations in trust; and finally, what he calls the "functional approach" whereby the powers of existing international and technical organizations, such as the International Civil Aviation Authority or the World Meteorological Organization, should be recognized as providing the effective authority within their spheres of activity. This functional approach is attractive, but whatever the mode of evolution favoured, Dr. Bertram is clearly right in calling for some immediate and realistic thinking, both in Britain and in the Commonwealth, concerning our Antarctic aspirations and responsibilities.
David L. Linton

\section{ROTHAMSTED EXPERIMENTAL STATION}

\section{REPORT FOR 1957}

$\mathrm{E}^{\mathrm{v}}$ VERY year, when reading the annual report of the Rothamsted Experimental Station*, one is impressed anew by the scope of the work undertaken by Britain's oldest agricultural research centre. Not only British but Commonwealth problems receive regular attention, a fact well shown by the list of overseas visits and secondments of staff for the purposes of specialist consultation or investigation. The present report is the fiftieth of the series, and a valuable inclusion is a summary index covering this period. It is, indeed, a concise history of the development of Rothamsted in the present century.

Comprising, as it does, the work of fifteen departments as well as such activities as soil surveys at home and abroad, it is not possible for any single reviewer to discuss critically all the varied information contained in the report. The main lines along which research is proceeding may, however, be indicated.

In the Physics Department work has continued on the structure and properties of soil, particularly clays. Studies on these suggest that, when they are

* Rothamsted Experimental Station (Lawes Agricultural Trust). Report for 1957 (With 50-Year Index, 1908-57). Pp. 316. (Harpenden :
Rothamsted Experimental Station, 1958.) 10s. wetted slowly, subsequent flooding does not produce the slaking effect that it has on a dry clay and that the shattering effect of entrapped air seems to be very slight. The practical effect of this seems to be that, in a saturated atmosphere, the slaking action of rain on dry field soil is confined to the surface, since the diffusion of water vapour downwards ahead of the liquid wetting front permits a controlled swelling of the clay without disruption. Other investigations have dealt with temperature and water relations in soil and with crop environment with particular emphasis, during the period under review, on spring wheat. It has been shown that short-period fluctuations in the rate of water uptake by wheat follow closely the changes in sunlight intensity.

The Chemistry Department has continued its experiments on the use of fertilizers and it is clear that seasonal variations in crop response to nitrogen are so large that it is not yet possible to make prac. tical recommendations to the farmer with the certainty that he would like. This is not surprising since the maximum profit from any particular crop does not depend on one factor alone. One interesting finding was that heavy dressings of calcium nitrate 